\title{
A IMPORTÂNCIA E A RESPONSABILIDADE DA GESTÃo FINANCEIRA NA EMPRESA.
}

\author{
Profa.Ângela Cheng \\ Professora do Departamento de Contabilidade e Atuaria \\ da Faculdade de economia e administração da Universidade de São Paulo (FEA/USP)
}

Profa. Márcia Martins Mendes

Professora do Departamento de Contabilidade e Atuaria da faculdade de Economia e administração da Universidade de São Paulo(FEA / USP)

\section{(*) Trabalho apresentado na XVIII Conferência Interamericana de Contabilidade - 1.989 - Paraguai}

\section{RESUMO}

A empresa vista como um sistema aberto, possui uma missão, um modelo de gestão, uma estrutura organizacional, um processo de planejamento e controle e um sistema de informações, que se interrelacionam buscando atingir a eficácia.

Entendemos como modelo de gestão os princípios de administração que influenciarão o processo decisório, a estrutura organizacional e o sistema de informações.

Tendo sido definido os princípios, a empresa passará a delinear sua estrutura organizacional coerentemente com seu processo de decisão.

Para avaliarmos o desempenho dos gestores acreditamos que a empresa deva ser dividida em áreas de responsabilidade. E de acordo com a necessidade, subdivididas em unidades de acumulação (centro de custos, resultados e investimentos).

Para dar suporte ao processo decisório a empresa deve estruturar adequadamente o sistema de informações que, a margem de contribuição, preço de transferência e custo de oportunidade. Dentro deste contexto enfocamos a gestão financeira, pois entendemos que este é um aspecto importante e que, se bem conduzido, poderá contribuir para a eficácia gerencial.

Gestão Financeira pode ser definida como a gestão dos fluxos monetários derivados da atividade operacional, em termos de suas respectivas ocorrências no tempo. Entretanto que ela não é função exclusiva do gestor da... "Área financeira", mas de todos os gestores das diversas áreas de responsabilidade.

Propusemos, então, um mecanismo capaz de mensurar o resultado de cada área pela gestão financeira. Neste mecanismo cada área seria vista como uma empresa, tendo seu planejamento e controle financeiro, assim como relatórios, possibilitando avaliar adequadamente o desempenho dos gestores.

Entendemos que os gestores devem ser avaliados somente por aquilo sobre o que têm responsabilidade e autoridade e, neste sentido, tratamos o custo de oportunidade como um item efetivo de custo. Pois, sendo este o valor da melhor oportunidade desprezada nas mesmas condições de risco, é o retorno mínimo desejado pelos acionistas. 
Sob este enfoque de avaliação da gestão financeira, acreditamos que os gestores terão mais informações para a tomada de decisão e, portanto, menor risco de erro, dando mais um passo para atingir a eficácia gerencial e contribuindo para o crescimento da Empresa.

\section{QUADRO REFERENCIAL BÁSICO}

Estamos pressupondo um contexto em que uma dada empresa tem definidos sua missão e um dado modelo de gestão e, além disso, caracteriza-se como um sistema aberto.

A partir do modelo de gestão, que deve considerar a missão determinada ou principal gestores da empresa, define-se uma estrutura organizacional, os contornos de um processo de tomada de decisão (Processo de planejamento e controle) e de um sistema de informação que o apóia.

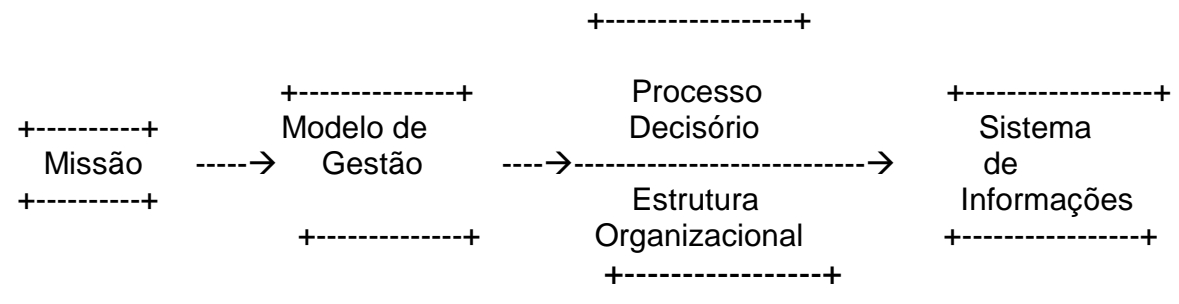

No modelo de gestão devem estar definidos os princípios de administração da empresa, ou seja, o conjunto de regras básicas que orientam a gestão. Definição de indicadores de desempenho, grau de centralização ou descentralização, nível de controle são exemplos importantes de diretrizes que devem ser aqui determinados.

A estrutura organizacional deve ser um elemento facilitador de consecução da missão, dados os processos de tomada de decisões. Assim, em função do modelo de gestão, os seguintes aspectos essenciais da estrutura organizacional precisam ser definidos. Grau de Centralização ou descentralização, amplitude de controle, natureza da divisionalização (Centros de custos, resultados, investimentos).

Entendemos que para uma gestão atingir seus objetivos de forma satisfatória, a estrutura da empresa deve ser

- Descentralizada;

- O Controle deve ser exercido em cada área de responsabilidade, entendida esta como unidades administrativas, as quais possuem gestores com funções, responsabilidades e autoridades claramente definidas e compatíveis entre si;

- $\quad$ Em termos de acumulação, deve estar dividida em três tipos de unidades: centros de custo, centros de resultados e centros de investimento, sendo utilizados de acordo com a necessidade de avaliação.

O processo decisório diz respeito às etapas do ciclo de planejamento e a seleção entre alternativas de curso de ação futura tendo em vista um determinado cenário esperado.

O planejamento costuma ser dividido em estratégico e operacional. O planejamento estratégico define as diretrizes, definidas planas, políticas e objetivos planejados os gestores necessitam exercer controle. O objetivo do processo de controle é detectar desvios dos planos e, em função disso, viabilizar a implantação de ações corretivas. Todo processo decisório da empresa está apoiado num elemento de fundamental importância, que é o sistema de informação. 
Sistema de informação é basicamente um conjunto de subsistemas de informações que integrarem na consecução de um objetivo comum, que é fornecer eficientemente informações úteis aos seus usuários. Assim sendo, informações são dados que foram selecionados e organizados, tornando-se relevantes e úteis para os tomadores de decisão.

Para fins deste trabalho trataremos do usuário interno à empresa, ou seja, daqueles que necessitam da informação para gerir adequadamente os recursos disponíveis em suas atividades.

O sistema de informações deve ser elaborado visando atender as necessidades dos gestores, tomadores de decisão e neste sentido acreditam que deva ser estruturado com conceitos de avaliação que permitam medir resultados e avaliar desempenhos de forma adequada. Alguns destes conceitos, a nosso ver, seriam:

- Custeio variável: a utilização de métodos de custeio variável para a apropriação dos custos nos centros de acumulação apóia-se na idéia de analisar os custos em função do seu comportamento, ou seja, somente os custos variáveis (diretamente relacionados com o nível de produção) são atribuídos aos produtos e serviços.

- Margem de contribuição: Os resultados de uma área podem ser analisados através da demonstração (receitas, custos e despesas variáveis). A Margem de contribuição propícia a

Análise e tomada de decisão em nível de produtos, divisões, filiais e outros, possibilitando ainda, uma clara visão sobra à formação dos resultados totais.

Preço de transferência: pode ser definido como o valor da mensuração das transações que ocorrem entre as unidades administrativas de uma empresa. Através da utilização do conceito de preço de transferência é possível medir resultados de cada área para melhor avaliar o retorno sobre os recursos investidos.

- $\quad$ Custo de oportunidade: Entendido este como valor da melhor oportunidade desprezada, nas mesmas condições de risco e deve ser encarado como item efetivo de custo.

Em resumo, temos que a partir do modelo de gestão definem-se uma estrutura organizacional e o processo decisório, que devem ser suportados por um adequado sistema de informações. Além disto cada área de responsabilidade deve organizar-se, ter o seu planejamento e o seu controle, de forma que atinja seus objetivos e conduza a empresa a alcançar os melhores resultados possíveis. Portanto, para que a empresa consiga ser eficaz é necessário que todas as áreas participem com os seus melhores esforços.

Analisamos, em seguida, um dos principais fatores que influenciam a eficácia gerencial, qual seja, a gestão financeira.

\section{II-GESTÃO FINANCEIRA E MECANISMO DE MENSURAÇÃO PROPOSTO}

Gestão financeira pode ser definida como a gestão dos fluxos Monetários derivados da atividade operacional da empresa, em termos de suas respectivas ocorrências no tempo. Ela objetiva encontrar o equilíbrio entre a "rentabilidade" (maximização dos retornos dos proprietários da empresa) e a "liquidez"(que se refere à capacidade de a empresa honrar seus compromissos nos prazos contratados). Isto é, está implícita na necessidade da Gestão financeira a busca do equilíbrio entre gerar lucros e manter caixa.

Assim sendo, pode-se dizer que a gestão financeira esta preocupada com a administração das entradas e saídas de recursos monetários provenientes da atividade operacional da empresa, ou seja, com a administração do fluxo de disponibilidade da empresa.

Vejamos inicialmente como o fluxo de caixa da empresa é tradicionalmente apresentado (Figura 1). Ele constitui-se de colunas verticais referentes ao tempo (dias, meses, anos, etc.) e contas colocadas na horizontal, representativas dos diferentes tipos de entradas e saídas de dinheiro da empresa. Além dessas contas, dispõe-se na horizontal o saldo: 
- Inicial: Refere-se ao saldo remanescente do período imediatamente anterior ao analisado (dia, mês, ano, etc.)

- Disponível: resulta da soma do salto inicial e o total de entradas, portanto é igual ao total que a empresa dispõe no momento para fazer face ás saída de caixa necessárias.

- Final: é o resultado da subtração, saldo disponível menos total das saídas.

Obrigatoriamente os três tipos de saldo devem ser positivos, dado que já se incluem nas entradas as operações financeiras (empréstimos/financiamento).

Usualmente entende-se que o responsável pelo planejamento, operacionalização e controle do fluxo (receitas, despesas financeiras) é o gestor da área financeira. Entendemos ser esta uma visão simplista e equivocada do problema. Dado que o fluxo caixa nada mais é do que a distribuição no tempo de todas entradas e saídas de numerário geradas pelas atividades da empresa, conclui-se que o gestor da área financeira absolutamente não pode ser o único responsável por ele. Cada gestor das diversas áreas da empresa divide esta responsabilidade com o gestor financeiro a partir do momento em que cada decisão tomada impacta de alguma forma o fluxo de caixa.

Pode-se visualizar melhor o problema, simplesmente alterando a forma de disposição das contas dos fluxos, como pode ser visto na (figura 2).

Tendo em vista o que foi exposto acima, pode-se dizer que todos os gestores devem ser avaliados pelos seus envolvimentos com a gestão financeira.

Na tentativa de melhor explicar o que foi dito até aqui, vamos relembrar o conceito de "ciclo de caixa".

O ciclo de caixa é o "período de tempo que vai do ponto em que a empresa faz um desembolso para adquirir matérias-primas, até o ponto em que é recebido o dinheiro da venda do produto acabado, feito com aquelas matérias primas".(1)

\section{(1) Gitman, Laurence J. - "Princípios de Administração Financeira"- Harbia Editora, 1.978}




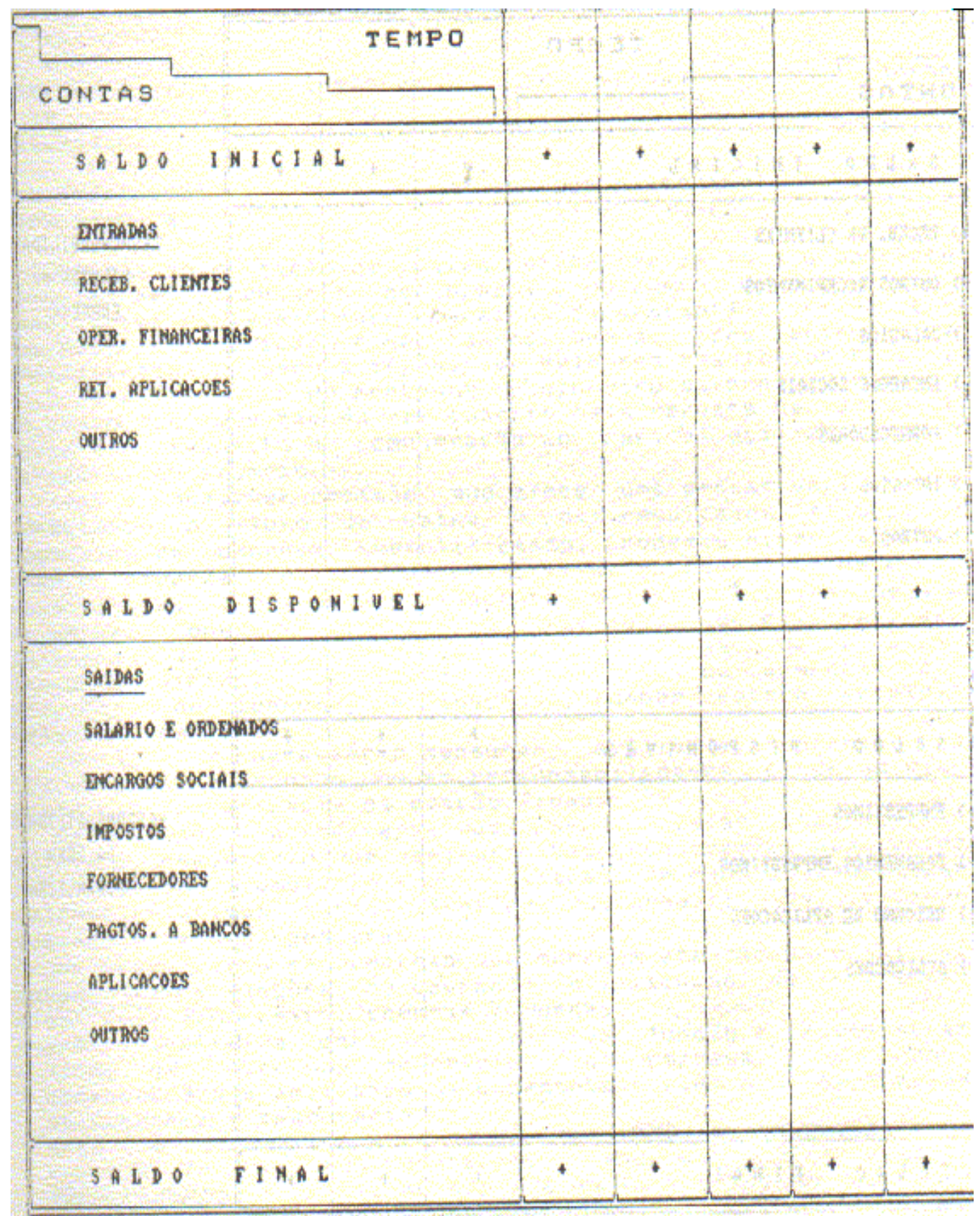

ESAIBA 1 


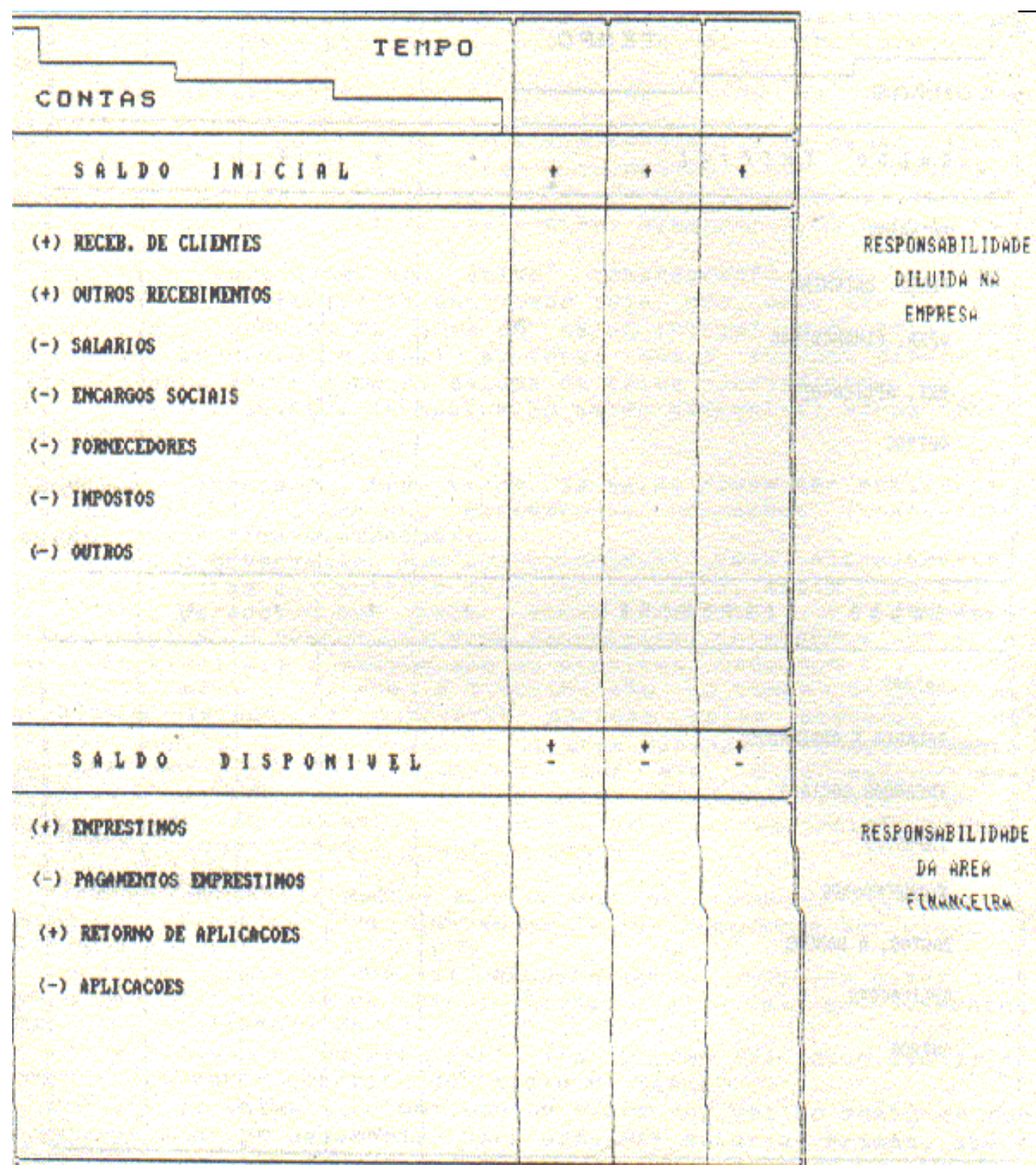

Assim o esquema do ciclo de caixa da empresa seria:

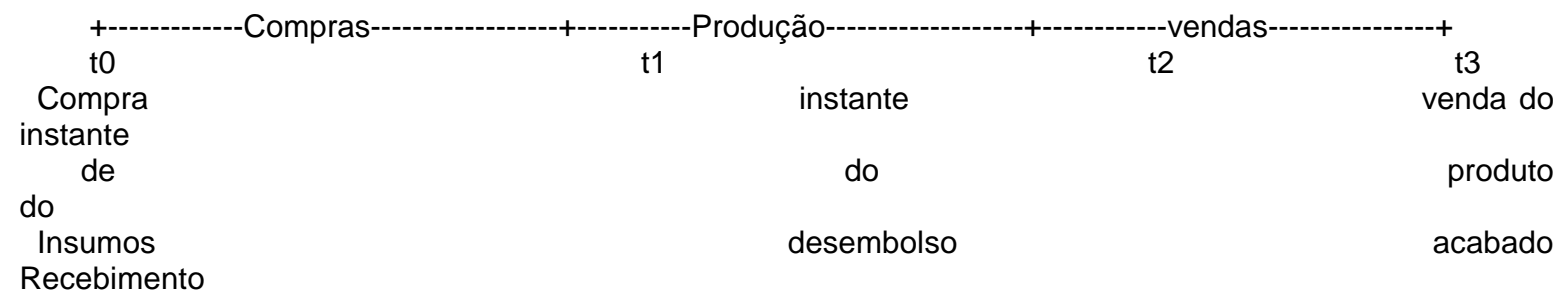

Bem disponível 
Observando o ciclo de caixa, visualiza-se que o montante de dinheiro em circulação, os prazos e os custos do dinheiro são importantes variáveis para analise da gestão financeira. E para que esta seja eficaz é necessário que as três variáveis sejam administradas de modo a atingir os melhores resultados possíveis.

O fato de haver um montante de dinheiro disponível representa um custo que deve também ser coberto pela receita de vendas. Esse custo diz respeito à remuneração do capital utilizado, seja de terceiros ou próprio.

Toda e qualquer decisão que afete uma dessas variáveis está impactando o fluxo de caixa e os resultados financeiro e econômico da empresa. Exemplificando, podemos dizer que, se a área de compras conseguir um prazo maior ou conseguir um desconto maior estará afetando positivamente o fluxo de caixa. Se a área de vendas conseguir diminuir o prazo dado aos clientes, estará influenciando positivamente o fluxo de caixa. Se a área de produção diminuir o

tempo de produção ou aumentar a sua eficiência no consumo de insumos, também estará proporcionando melhores resultados.

Portanto, é necessário mensurar, avaliar e controlar essas influências de acordo com as responsabilidades, tendo em vista a consecução da eficácia da gestão financeira.

Assim sendo, acredita-se que para a gestão financeira ser eficaz é necessário que sejam feitas mensurações nas unidades contábeis de acumulação e consolidadas, de modo a identificar, os valores relativos a cada área de responsabilidade, visando à avaliação de seus gestores.

Há três áreas na empresa que merecem atenção especial, visto desempenharem funções de captação e aplicação de recursos São elas: área financeira, compras e vendas.

- Área financeira: Entende-se que sua função é administrar o fluxo de recursos monetários da empresa suprindo as necessidades e aplicando os excedentes, além de suas atividades de cobrança e tesouraria.

- Área de compras: A área de compras pode ser entendida como um captador de recursos monetários quando ao negociar prazos com fornecedores, propicia ou não à área financeira um "empréstimo" a uma determinada taxa.

- Área de vendas: vendas, por sua vez, funcionam como um aplicador na empresa, ao conceder prazos aos clientes. Pode-se pensar que, ao invés de realizar uma aplicação no mercado financeiro, a empresa aplica as contas a receber.

Pode-se então imaginar que cada área de responsabilidade funciona como uma pequena empresa.

Cada área possui seus ativos, recebes os insumos necessários, processa-os de modo a gerar produtos e/ou serviços acabados (do ponto de vista da área, podendo não ser acabado em termos da empresa), que serão repassados a clientes ou às outras áreas.

Seguindo este raciocínio, cada área de responsabilidade deverá ter seu próprio orçamento e respectivos demonstrativos contábeis, através da subdivisão da área em unidade de acumulação (Centros de custo, resultados e/ou investimentos) e sua consolidação.

Desta forma, se cada área é uma pequena empresa há também um fluxo de caixa e resultados derivados da gestão financeira, que devem ser planejados e controlados, então para haver uma gestão financeira eficaz, a empresa deve reconhecer que ela é responsabilidade de todas as áreas e não só da área financeira. E sendo assim todas as áreas devem planejar e controlar seus recursos de forma que os parâmetros básicos da gestão financeira (montante de dinheiro, prazo e custo de capital) sejam bem administrados.

Para que a empresa consiga mensurar e avaliar a gestão financeira de forma adequada, pode-se imaginar cada área como uma empresa com seu orçamento e demais relatórios contábeis. Estes dados serão acumulados em centros de custo, resultado ou investimento e deverão ser consolidados e uma área de responsabilidade, para que se possa avaliar o desempenho do gestor.

É de fundamental importância que estes dados sejam informados de forma objetiva, clara e oportuna, a fim de dar o suporte adequado às tomadas de decisão e estas consigam auxiliar o crescimento da empresa.

Sugere-se abaixo um mecanismo de mensuração da gestão financeira de cada área. 


\section{MECANISMO DE MENSURAÇÃO}

Para facilitar o raciocínio no desenvolvimento do mecanismo de mensuração, consideramos a utilização de uma moeda de poder aquisitivo constante. $\mathrm{Na}$ empresa as áreas de responsabilidade terão um fluxo de caixa e resultados derivados da gestão financeira, os quais devem ser planejados e controlados.

Sendo a área uma empresa, a cada instante de incursão de recursos a área deveria efetuar um pagamento. Mas como poderia faze-lo se seu único recebimento se daria no instante da venda (supondo que as áreas devam efetuar todas as compras e vendas a vista)?

O fluxo de caixa da área de responsabilidade seria algo como:

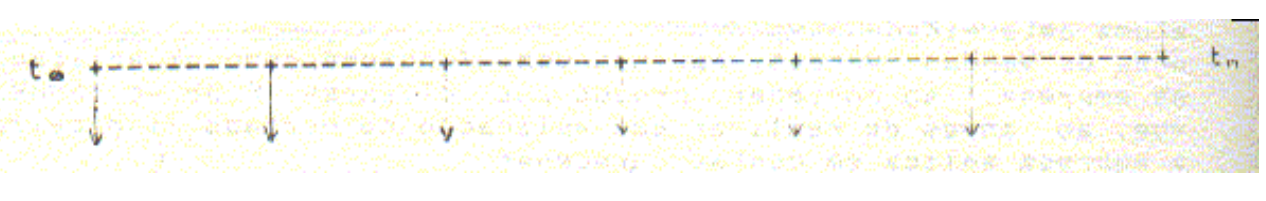

Pode-se acoplar a esta idéia o fato de que existe um custo financeiro relativo a um determinado montante de recursos monetários mantidos à disposição das atividades produtivas da empresa. $\mathrm{O}$ custo financeiro é diretamente proporcional às três variáveis: Valor, tempo e taxa.

Este custo financeiro pode ser definido como o custo do capital alocado à empresa (próprio + terceiros). Assim os resultados de cada área deverão ser analisados, incluindo-se o custo do capital empregado.

Dentro da idéia que cada área é uma empresa, ela necessita de empréstimos para suprir todas as necessidades existentes no período (t0-t0), sendo que no momento t0 a área estaria apta a devolver o empréstimo.

A área financeira deve funcionar como um banco, concedendo a cada área empréstimos à taxa do custo de oportunidade do acionista, como já definimos.

A cada instante de ocorrência de entrada de recursos em cada área, será contabilizado um empréstimo em uma conta credora na área solicitante e devedora na área financeira.

É importante lembrar que todos os valores de custos devem necessariamente corresponder aos preços à vista dos bens/serviços, dados que diferenciais entre preços à vista e os a prazo, eventualmente pagos pela empresa, serão custo financeiro da área de compras.

\section{Exemplos:}

Entrada de matéria-prima na área $A$, no valor de $R \$ 250,00$

\section{Área financeira}

\begin{tabular}{c} 
Bens em Elaboração \\
\hline 250,00
\end{tabular}

“Caixas” (Isumos)

250,00 
250,00

250,00

Em decorrência da conta empréstimo da Área A, haverá uma conta de custos financeiros internos, que receberá o lançamento relativo ao tempo em que os $\$ 250,00$ permanecerão à disposição da área, calculado com base na taxa cobrada pela área do produto elaborado com esta matéria prima, a área $\mathrm{A}$ estará apta a devolver o empréstimo, devendo o custo financeiro ser calculado até este instante.

Dissemos que a idéia de custos financeiros derivados do ciclo de caixa pode ser comparada ao custo do capital alocado.

Para fins de mensuração na empresa cabe dizer que, independentemente da composição do capital, da empresa entre terceiros e próprio, toda e qualquer operação deve ser avaliada com base no custo do capital próprio, dado que este é o retorno mínimo obrigatório esperado.

Utilizaremos dessa forma o custo-oportunidade, servindo para avaliar a gestão financeira e completando os itens de custo dos produtos.

A área $A$ desta forma terá inserido em seus custos um item a mais que intitulamos de custo financeiro interno e que equivale ao custo-oportunidade do acionista.

Este custo poderá, se bem identificado, ser alocado diretamente aos produtos, visto que para cada item de custo incorrido há, em contrapartida, um valor de custo financeiro interno.

O demonstrativo de resultado da área $A$, supondo-se que seja produzido apenas um produto $X$, poderá ser apresentado da seguinte forma:

\section{Demonstrativos de resultados da área $A$}

\section{Receita do produto $X$}

(-) Preço de transferência do produto $X$ recebido da área anterior

(-) Custo de mão-de-obra do produto $X$

(-) Custo de matéria-prima do produto $X$

(-) Custos financeiros internos do produto $X$

(=) Margem de contribuição do produto $\mathrm{X}$ na área $\mathrm{A}$

(-) Outros custos da área A

(-) Outros custos financeiros internos da área $\mathrm{A}$

(=) Resultado da área A

O mecanismo ilustrado é indicado para todas as áreas da empresa, sendo que as áreas de apoio mensurarão o resultado dos serviços prestados às outras áreas.

Devemos ainda acrescentar os casos particulares de compras e vendas, que como vimos funciona como captador e aplicador de recursos.

Em compras existe o caso especial de compras a prazo. Compras serão oneradas pelo valor do diferencial pelo preço à vista e o preço a prazo, mas por outro lado deverá ser beneficiado, por um valor determinado pela área financeira, pelo fato de só ter disposto do dinheiro " $X$ " dias após a compra.

Compras deverão ser informadas pela área financeira a respeito do dinheiro no mercado financeiro (padrão de caixa), para que possa balizar suas decisões de compra à vista ou a prazo.

No caso de vendas, esta obterá os resultados do diferencial dos preços à vista e a prazo cobrado dos clientes. Em contrapartida a essa receita, será penalizada pela retenção, por um certo prazo, dos recursos alocados ao Contas a receber. 
Esta forma de apuração de resultados também é valida em economias inflacionarias, podendo ser associada ao mesmo mecanismo de atualização monetária. Neste caso deverão ser registrados os valores à vista, considerando-se não somente a taxa de inflação, mas também a taxa de juros embutida nas vendas e compras a prazo.

\section{III-Conclusão}

O presente trabalho teve como preocupação básica o estudo do problema de mensuração do ambiente de Gestão Financeira.

Tendo em vista os aspectos ligados ao problema de mensuração, buscamos discutir e enfatizar a atribuição de responsabilidades pela Gestão Financeira, demonstrando que as mesmas não são exclusivas do que se costuma chamar "área financeira" mas ao contrario estão amplamente diluídas nas diferentes áreas de responsabilidade da empresa.

Para ilustrar e reforçar essa idéia, nosso argumento se apoiou no conceito do ciclo de caixa, o qual permitiu visualizar claramente a influência das diversas áreas de responsabilidade sobre o nível de recursos monetário da empresa e, por conseqüência sobre seus efeitos econômicos.

Desse modo, como forma de viabilizar a avaliação de desempenho dos diversos gestores no âmbio da Gestão Financeira, propusemos um mecanismo de mensuração onde cada área seria vista como uma empresa e, desta forma,m teria seu próprio planejamento e controle financeiro e assim se poderia separar responsabilidade e identificar resultados de forma coerente.

O Mecanismo apresentado tornou possível a separação dos resultados econômicos provocados pela gestão financeira dos resultados econômicos derivados das demais gestões (operacional e econômica).

Com a doação deste mecanismo a informação, no âmbio da Gestão Financeira, fica mais transparente. Cada gestor será cobrado por aquilo que tem responsabilidade e autoridade, ou seja, também pelo impacto que sua área causa no resultado gerado pela administração dos recursos monetários.

Consideramos importante incluirmos como item de custo o custo de oportunidade, pois sendo este o valor da melhor alternativa desprezada, nas mesmas condições de risco, entendemos que ele é o retorno mínimo desejado pelos acionistas e desta forma o resultado de cada área deverá cobrir este valor.

A Partir do momento que cada área fizer seu planejamento e controle financeiro terá seu próprio fluxo de caixa, orçamento e relatório contábeis, as informações poderão ser mais precisas e oportunas, auxiliando na tomada de decisão, com maior grau de segurança e, portanto aumentando a eficácia gerencial e contribuindo para o crescimento da empresa.

\section{BIBLIOGRAFIA}

Anchieta, A . C., Cammas, C.A . V.Mendes, M.M.,Paccez, J.D.,

Rosano, L.C. - Padrões na Mensuração do Resultado de Produções de Serviços - Trabalho da Disciplina Análise de Custos - FEA/USP, 1.988

Bio, S.R. - Sistema de Informação - Um Enfoque Gerencial - São Paulo, Atlas, 1.985

Cheng, A ., Francini, C.M.B., Dosvaldo, J. Godoy, L.C.

Muccillo, J. - Padrões na Mensuração do Resultado Econômico da Gestão Financeira - Trabalho da Disciplina Análise de Custos - FEA/USP, 1.988

Gitman, L. J. - Principios de Administração Financeira - Editora Harbra \& Row do Brasil, 1.978

Nakagawa, M. - Estudos de Alguns Aspectos de Controladoria que Contribuem para a eficácia Gerencial - Tese de Doutoramento - FEA/USP, 1.987 